MUZIKOLOŠKI ZBORNIK - MUSICOLOGICAL ANNUAL IX, LJUBLJANA 1973

UDK 78.01

\title{
ZVOK KOT GRADIVO ALI ZNAK IN SMISEL GLASBE
}

Ivo Supičić (Zagreb)

Že Hegel je spoznal bistveno istovetnost glasbe in zvoka. Po Heglu je elementarna moč glasbe $v$ tem, da je v samem elementu, v katerem se ta umetnost odvija, torej v zvoku. Poslušalec je ganjen po tem elementu ne zaradi te ali one lastnosti, zaradi te ali one določene vsebine, ampak zato, ker glasba deluje na samo središče človekovega duhovnega življenja, ki se tako začenja gibati in je spodbujeno $\mathrm{k}$ dejavnosti. ${ }^{1}$ Toda $\mathrm{v}$ nasprotju $\mathrm{s}$ Heglom izhaja učinek glasbe ne le iz. zvoka kot elementa, katerega uporablja. Kvaliteta njenega delovanja, njen značaj in intenziteta so odvisne tudi od vsebine glasbe, organizacije zvokov $\mathrm{v}$ glasbenem delu, čeprav je nesporno, da je to delovanje bistveno povezano $\mathrm{z}$ delovanjem osnovnega elementa, ki ustvarja glasbo, ta pa je poleg ritma zvok. »V primerjavi $\mathrm{z}$ drugimi umetnostmi ima glasba to pomembno originalnost, da je dosti bližja kot ostale čistemu občutku.... Glasba je že zasnovana ... v zvočnosti «, ${ }^{2}$ in to zato, ker ni zvok povsem indeterminirano gradivo, ampak je specifična formalna materija, ${ }^{3}$ je že vnaprej določena za oblikovanje ali strukturiranje določene vrste $\mathrm{v}$ glasbenem delu. Kakor formulira Gisèle Brelet, se zdi, kot da glasba v zvoku dremlje: v njem je dejansko prisotna. V zvezi s tem je primerno razmisliti, ali je glede na ekspresivne možnosti glasbe prav tako nepravilno imeti zvok v bistvu za znak ali pa ga imeti samo za objekt ali gradivo.

Hanslick je prispeval veliko pomembnost eni, zanj temeljni razliki: v govoru je zvok samo sredstvo, ki ga uporabljamo za izražanje stvari, ki je temu sredstvu čisto tuja; v glasbi pa je zvok cilj in samemu sebı lasten namen. ${ }^{4}$ Mnogi avtorji so poudarjali prvotno prev.).

1 Prim. Hegel G. W. F., Esthétique, zv. III, 313, Paris 1944 (francoski

Brelet G., Le temps musical, zv. I, Paris 1949, 66.

O formalni materiji v glasbi prim. Supičić I., Muzička materija i forma, Arti Musices, zv. II, Zagreb 1971, 11.

${ }^{4}$ Prim. Hanslick E., Vom Musikalisch-Schönen, ein Beitrag zur Revision der Ästhetik der Tonkunst, Wien 1854. 
vrednost zvoka kot objekta. Tako je Maurice Pradines pisal: »Ko odvrže svoj označujoč privid, svojo livrejo, se reši svoje naloge in odvrže svoje sporočilo, je zvok samo zvok. Ta preneha, sicer že tako slabo, reprezentirati in se sam prezentira. Ločen je od svoje vrednosti znaka in dosledno od svoje biološke in praktične funkcije. ${ }^{5} \mathrm{Ker}$ zvok nima pojmovnega pomena, to je ker ni pojmovno znak, se lahko zdi tako gledanje, ki reducira zvok na objekt, na prvi pogled pravilno. Vendar, če ton nima biološke in praktične funkcije, še to ne pomeni, da nima ekspresivne, niti iz tega ne izhaja, da ni znak (za katerega tudi ni nujno, da bi imel sam po sebi tako biološko in praktično funkcijo). V vsakdanji praksi je zvočnost kvaliteta objekta, glede katerega nas pogosto informira. To velja zlasti za šume in krik, ki neposredno informirata o svojem viru in včasih tudi o vzroku nastanka. Nasprotno pa ima $\mathrm{v}$ glasbi zvok vrednost $\mathrm{v}$ sebi in za samega sebe ne glede na svoji vir ali vzrok nastanka; tu je osredotočena pozornost poslušalca na zvok kot zvok. Toda prav zato, ker prevzema $\mathrm{v}$ glasbi zvok posebno funkcijo, ni dovolj postaviti problem izključno na fizično raven: glasba je estetska tvorba in tako je treba razpravljati o zvoku kot objektu in znaku tudi na umetniški ravni. Ta raven pa vključuje dosti bolj zapletene človeške in kulturne realnosti, ki zahtevajo temeljitejši prijem.

$\mathrm{Na}$ fizični ravni ima zvok določeno "naravno estetičnost«. V tej perspektivi je zvok v bistvu samo objekt, objekt kot fizični fenomen in gradivo, oziroma temelj, na katerem gradi glasba lasten umetniški svet. Specifičnost in avtonomija zvoka imata lastno vrednost in lastne zakone sicer ne samo na fizični, ampak tudi na estetski ravni. Avtorji kot Paradines, ki poudarjajo ta aspekt, imajo čisto prav. $\mathrm{Ne}$ gre za to, da se vprašujemo o zvoku kot objektu, pa tudi ne za to, da osporavamo, da ima zvok v glasbi vedno primat kot objekt. Problem je le v tem, ali je zvok izključno objekt ali je še nekaj več kot to. Objektivnost zvoka seveda ni istega reda kot objektivnost vizualno zaznavnih dejstev. Primarna dimenzija zvoka ni prostor, kateremu primarno pripada svet vizualnih objektov, ampak je dimenzija časa. Razen tega se vizualni predmeti predstavljajo človeku kot njemu zunanji svet, ki je od njegove fizikalne biti oddaljen, medtem ko se zvočni objekti insinuirajo $\mathrm{v}$ intimnost človekove psihične in duhovne biti ter jo napolnjujejo s svojim trajanjem. Glasba je umetnost časa, ker zvok traja v času. Toda priznati zvoku vrednost znaka ne pomeni, da mu odrekamo naravo objekta. To tudi ne pomeni vnašati $\mathrm{v}$ glasbo nek njej tuj element, jo izpostavljati neke vrste notranjemu protislovju, niti jo poniževati s tem, da ji pripisujemo izvenzvočne kvalitete. Vendar pa se glede na naziranja nekaterih estetov zdi, kot da bi glasba izgubila nekaj od svoje estetske vrednosti, če bi ji priznali ekspresivno vrednost. $\mathrm{Da}$ se izognemo takšnim alternativam, je potrebno kar najbolj jasno razlikovati estetsko in ekspresivno vrednost

${ }^{5}$ Pradines M., Traité de psychologie, zv. II, Le génie humain, ses oeuvres, Paris 1946, 22. 
glasbe. Glasba preneha obstajati kot umetniška tvorba, ko prenelıa njena estetska vrednost, ki predstavlja njeno bistveno in osnovno dovršenost, brez katere glasbenega smisla nekega dela ni. Toda estetska vrednost glasbenega dela ni nezdružljiva z njegovo ekspresivno vrednostjo, čeprav sta si lahko ti vrednosti v samem delu do neke mere $\mathrm{v}$ določenem nasprotju. Vendar ekspresivni element vedno bolj ali manj predpostavlja estetski element. Vsekakor v glasbi ni mogoče graditi ekspresivnosti izven estetskega oblikovanja ali formalne organizacije zvoka.

Priznati pomenske lastnosti zvoka in priznati glasbi stalne izrazne možnosti nikakor ne pomeni podrediti glasbeno umetnost enemu elementu, ki bi ji bil tuj in nasproten, ali reducirati zvok predvsem na znak. Narava zvoka kot objekta se v ničemur ne spremeni, če prevzame funkcijo znaka: njegove fizične in estetske lastnosti ostanejo iste. Zvok dobi samo dodatno vrednost, ki ne odtujuje njegovo naravo. Ta vrednost je pač vrednost za človeka, za njegov um in moč razumevanja. Da bi slišali, doživeli in razumeli zvoke, ni potrebno vedeti, od kod izhajajo, kateri je njihov zvočni vir, niti ne, kakšen je način njihovega nastanka. »Medtem ko je v vsakdanji praksi zvočnost kvaliteta nekega objekta, na katerega se nanaša, ima $\mathrm{v}$ glasbeni praksi vrednost $\mathrm{v}$ sebi in po sebi. V tej idealizaciji pa se ne sme niti najmanj videti neke vrste ,umetniško laž', katere namen bi bil, da nas odvrne od vsakdanjega sveta, ampak nasprotno realizacijo skrite biti zvoka. ${ }^{6}$ Vsekakor zvok ni nikakor ponižan ali omalovaževan $\mathrm{z}$ estetskega vidika oziroma $\mathrm{v}$ estetskem pogledu, če preseže po svoji vrednosti pomen objekta in prevzame vrednošt znaka. Toda ali je zvok lahko znak in v kakšnem smislu?

Klasična definicija znaka kot id quod repraesentat aliud a se potentiae cognoscenti poudarja, da predstavlja znak spoznanju nekaj, kar on ni. Razlikovanja med naravnim in konvencionalnim znakom kakor tudi med spekulativnim in praktičnim znakom so nedvomno filozofsko upravičena. Na področju glasbene estetike je morda najbolj važno razlikovati formalni in instrumentalni znak. Formalni znak označuje izključno nekaj izven sebe, nekaj, kar on ni. Nasprotno označuje instrumentalni nekaj, kar ni on, vendar označuje pred tem tudi samega sebe, predstavlja torej spoznanje sebe in nečesa izven sebe.

Formalni ali čisti znak je pojem. Služi izključno za označevanje realnosti, ki ni on, ne da bi se pri tem prezentiral spoznanju kot tisto, kar je samo on. Besede jezika niso čisti ali formalni znaki, ampak so objekti, zvočni pojavi, čeprav označujejo pojme in kot objekti glede na to nimajo samostojne vrednosti. Besede spadajo v vrsto instrumentalnih znakov, ki so objekti in hkrati služijo za označevanje nečesa drugega izven sebe. Med instrumentalnimi znaki in realnostjo, ki jo označujejo, obstaja stalna analogija, neke skupne poteze. Takšna analogija ne obstoja med formalnim znakom in real-

${ }^{6}$ Brelet G., Le temps musical, zv. I, 87. 
nostjo, katero označuje, kajti pojmu, da bi označil npr. dvonožca, očitno ni potrebno dvoje nog ali nekaj podobnega. Pojem ne pripada fizičnem ali vidnemu svetu. Po svoji fizični naravi kakor tudi glede nato, kako je estetsko oblikovana, zvočnost ne pripada kategoriji formalnih ali čistih znakov: potemtakem more biti zvok samo instrumentalni znak. Kajti, kot smo že poudarili, zvok je predvsem objekt, lastnost instrumentalnega znaka pa je, da se prezentira najprej kot objekt, a potem tudi kot znak, ki označuje nekaj sebi zunanjega. Jasno je, da tu ne gre za časovno prednost, ampak samo za primarnost narave. Ta ontološka primarnost objekta pred znakom v zvoku vključuje seveda notranjo fizično nedeljivost zvoka. Vse, kar more zvok označevati izven sebe, prihaja izključno po njem kot objektu. Ko poslušalec posluša ekspresivno glasbeno delo, ne bo v časovnem smislu doživel najprej estetske kvalitete dela in šelı zatem njegove ekspresivne kvalitete, ampak jih doživlja neoddvojeno in istočasno. Toda vsaka označujoča funkcija zvoka ima po naravi sekundarni in ne primarni značaj.

Zvok spada torej $\mathrm{v}$ kategorijo instrumentalnega znaka. Znotraj te kategorije pa je pravzaprav znak-slika ali simbol. Vsaka slika namreč ni znak, a vsak znak ni slika. Slika izhaja iz nečesa drugega kot iz svojega principa in je podobna temu drugemu. Je celo lahko iste narave in ontološke stopnje kot princip, iz katerega izhaja. Otroci so npr. podoba svojih staršev, a niso njihov znak. Dim je znak ognja ali izgorevanja, a ni njuna podoba. Nasprotno je zvok eno in drugo, kadarkoli prevzame funkcijo oziroma vrednost simbola, to je znaka in slike (ko je hkrati "Bedeutung" in "Bild«). Tedaj je objekt, ki označuje nek drugi objekt s pomočjo analogije. $\mathrm{Ne}$ da bi prevzel funkcijo označevanja po analogiji, zvok ne bi mogel biti simbol in potemtakem tudi ne bi mogel imeti ekspresivne vrednosti. Te trditve postavljajo vrsto problemov, ki jih je treba po vrsti osvetliti.

Predvsem zvok more označevati nekaj izvenmuzikalnega edino na način, ki je lasten le njemu tudi v okviru njegovih lastnih možnosti označevanja. To pomeni, da ima področje zvočnega in potemtakem tudi glasbenega označevanja določene omejitve, ki jih postavlja sam zvok. Z drugimi besedami, zvok lahko označuje in izraža samo tiste izvenglasbene in nezvočne vsebine, ki so lahko po nekaterih svojih kvalitetah izražene $\mathrm{z}$ zvokom in ostalimi sredstvi, katere uporablja glasba. To vključuje, da analogije med zvokom in temi izvenmuzikalnimi vsebinami nujno ostajajo formalnega značaja. Glasba more označevati samo tisto, kar ustreza njenim možnostim. Nekatera področja kot npr. - da izberemo skrajni primer - področje matematičnih operacij, logičnih sklepanj ali kemičnih procesov, gotovo ne bo nikdar področje, ki bi ga mogel zvok stvarno označevati, enostavno zato ne, ker nima $\mathrm{z}$ njim formalnih analogij. Kompozicije kot Ionisation Edgarda Varèsea pretendirajo na označevanje - $\mathrm{v}$ tem primeru kemijskih procesov - bolj intencionalno (in s svojim naslovom) kot stvarno. Kar pa zadeva materialne ana- 
logije, so te strogo akustične vrste in obstajajo samo $\mathrm{v}$ zvočni reprodukciji izvenglasbenih zvočnih fenomenov znotraj glasbe, ki tedaj prevzema imitativne ali deskriptivne poteze.

Glede analogij v širšem smislu med glasbenimi in izvenglasbenimi vsebinami, ki jih lahko izraža skladatelj $\mathrm{v}$ svojem delu, naj omenim, da je te že preučeval $\mathrm{z}$. eksperimentalno metodo Julius Bahle. Kot je poudarila Gisèle Brelet,. se njegova metoda posebno prilagaja analizi ustvarjalnega procesa $\mathrm{v}$ ekspresivni glasbi, ker je ta proces $\mathrm{v}$ našem primeru med drugim tudi $\mathrm{v}$ tem, da postanejo psihološke vsebine, ki so na začetku tuje umetniškemu oblikovanju, na koncu umetniško oblikovane in da jih glasba asimilira. Ta metoda omogoča, da se najde konkretno naravo psiholoških vsebin, ki so pred oblikovanjem glasbenega dela, in da se spremlja njihovo postopno spreminjanje do trenutka, ko se pretvorijo $\mathrm{v}$ avtonomno glasbeno formo. ${ }^{7}$ Bahle "je lahko opazil, da je občutje toliko bolj obdarovano $z$ ustvarjalno silo kolikor je bogatejše $v$ formah in formalnih aspektih, ki se jih dà glasbeno izraziti... Delo se že išče v občutju, ki ga je glasbenik izbral, ker ga je ta izbral v tisti meri, kot je bilo že vnaprej določeno za svoje zvočno prevajanje zaradi njegove pristne in bistvene soglasnosti $\mathrm{z}$ glasbeno obliko. ${ }^{8}$ Bahle pravilno poudarja, da je "prehod ... od izvenglasbenega $\mathrm{k}$ glasbenemu, od vsebine $\mathrm{k}$ formi in od osebnosti $\mathrm{k}$ delu " $\mathrm{v}$ notranjih oblikah psihološkega sveta doživljanja. " ${ }^{9}$ Toda to področje že vključuje probleme, ki so povezani ne le z označevanjem, ampak tudi z izražanjem; to področje pa presega vprašanje zvoka kot objekta in znaka na fizični in estetski ravni, ker vključuje vprašanje odnosa med človekom in zvokom, katerega se on poslužuje na psihološki ravni. Ko puščamo ob strani to zadnje vprašanje, bi se morali za hip ustaviti ob vprašanju zvoka kot objekta in znaka na estetski ravni.

Ko je zvok izoliran, izločen iz celote drugih zvokov, s katerimi tvori določeno časovno in formalno, tj. estetsko "arhitekturo", izgubi kljub svoji »naravni estetskosti« značilnosti umetniške estetskosti. Še več: izgubi tudi nujno značilnosti umetniške ekspresivnosti. To pa zato, ker ni umetniške ekspresivnosti brez umetniške estetskosti. Zvoki dosežejo estetski smisel v glasbenem delu samo po formalnem oblikovanju, ki jih spravlja $v$ določene medsebojne odnose, ekspresivni smisel pa samo po svojem estetskem smislu, to je tudi po tem formalnem oblikovanju in po vzajemnih zvezah, v katere so postavljeni. Čeprav sta pojem in realnost lepote danes pri mnogih umetnikih $\mathrm{v}$ popolni nemilosti morda zato, ker so ju nekateri absolutizirali - čeprav gotovo ne samo zato - ostane prvo in najvišje načelo vsake umetnosti odkrivanje in ustvarjanje lepega. Zato je tudi glasbeno delo, ki ne zadovoljuje to načelo, $\mathrm{z}$ estetskega in umetniškega stališča nenaravno in tuje. $\mathrm{Da}$ je glasbeno delo estetsko in umetniško upravičeno, da je skratka umetnina, mora vsebovati in

7 Brelet G., ib., zv. II, 454-455.

8 Brelet G., ib., zv. II, 458 .

${ }^{9}$ Bahle J., Der' musikalische Schaffensprozess. Leipzig 1936, 74. 
izsevati lepoto, pa naj označuje neko izvenglasbeno vsebino ali ne oziroma ne glede na to, če je ekspresivno. Mimo vsakega označeva$n j a$ in izražanja pa čista glasba to, vsaj $v$ načelu, tudi vsebuje in izseva. Ekspresivna glasba se $\mathrm{v}$ tem ne razlikuje od čiste, vendar se za razliko od nje ne omejuje na izgrajevanje "glasbeno lepega", ampak nasprotno skozi to evocira in opisuje neke izvenmuzikalne vsebine. Samo tedaj, kadar se realizira $\mathrm{v}$ ekspresivnem glasbenem delu estetski element, dobi po njem zvočnost ekspresivno vrednost. To ne pomeni le, da je vsako umetniško vredno in estetsko lepo glasbeno delo tudi nujno ekspresivno (v smislu izražanja izvenglasbenih vsebin), pa prav tako ne, da je vsako ekspresivno glasbeno delo tudi nujno umetniško vredno in estetsko lepo. To pomeni le, da ekspresivnost bolj ali manj predpostavlja estetski element in da se po njem realizira. Samo ta element omogoča $v$ glasbenem delu estetsko izražanje izvenglasbenih vsebin. Glasbeni izraz je torej specifičen ne le po tem, da uporablja specifično gradivo, zvok, ampak tudi po tem, da ima za razliko od drugega, neumetniškega izražanja opravičilo in smisel samo kot umetniški, estetski izraz, ki je podvržen specifičnim zakonom glasbene umetnosti. Sicer pa, kot pripominja Gisèle Brelet, glasbeni zakoni niso akustični in fizikalni zakoni, ampak človeški in etični. »V zvoku se izraža $v$ svoji čistosti osnovni akt glasbene katarze. Zvok je zmaga nad šumom, ki je trzaj v objektu, in nad krikom, ki je krč biološkega bitja. Sum in tudi krik kot nenadna znaka sta diskontinuirana in kratkotrajna. Nasprotno pa je zvok definiran po svoji kontinuiteti in stalnosti: obstoja samo zato, ker ostaja istoveten samemu sebi... In medtem ko sta šum in krik prekinitev reda, je zvok zmaga reda in skladnosti ... Ko bi se človek prepustil svoji pasivnosti, ne bi bilo glasbe, celo ne zvokov, ampak bi bili le kriki. V zvočnem svetu kakor tudi v vsakdanjem svetu sé človekova volja postavlja nasproti upirajoči se naravi in njegovi naravi... Glasba je askeza od šuma $\mathrm{k}$ zvoku, od krika $\mathrm{k}$ petju, od grobe in nedisciplinirane afektivnosti $\mathrm{k}$ vodenemu in poduhovljenemu občutju ${ }^{10}$ Zvok se že na tej ravni in $\mathrm{v}$ tej perspektivi kaže kot rezultat aktivnosti človekove volje, miselnosti in čustvenosti, torej kot objekt, ki je tesno povezan s psihologijo in celo túdi $\mathrm{z}$ etiko svojega ustvarjalca. Nedvomno pa obstajajo tudi dosti globji aspekti te povezanosti. Toda tudi tu je mogoče videti, v kakšnem smislu in zakaj je lahko zvok znak in slika ali simbol $v$ umetnini: $v$ takšnem glasbenem delu postane on to ne samo zato, ker je po svojih značilnostih tega sposoben, ampak tudi zato, ker ga umetnik uporablja ali more uporabljati kot takšnega. To dejstvo pa razširja problem pomena zvoka in glasbe sploh na problem izražanja z zvokom in glasbo obče. Čeprav sta ta problema in ti realnosti $\mathrm{v}$ tesni zvezi, jih je vendarle treba razlikovati.

$\mathrm{K}$ prvi je treba še dodati, da izhaja označujoča vrednost zvoka iz dejstva, da se glasba ne zadovoljuje s fizikalnim proizvajanjem

${ }^{10}$ Brelet G., Musique et sagesse, La table ronde, 1962, št. 172, 64. 
zvoka kot objekta ali akustičnega fenomena, ampak teži nasprotno za ustvarjanjem specifične glasbene lepote kot za svojim osnovnim notranjim ciljem. Glasbeno ustvarjanje nima za najvišji notranji namen zvok in značilnost kot objekta ali njuno izključno fizikalno produciranje, ampak - s posredovanjem tega - lepoto, ki jo tvorita. Ta lepota seveda pripada zvočni materiji, pripada zvoku in zvočnosti, ki jo ustvarjata in iz katerih izhaja. Toda po svoji notranji strukturi, po tem da samo forma zvoke kot objekte ali gradivo organizira in oblikuje, glasbena lepota zvočno materijo tudi temeljito presega. ${ }^{11}$ Brez formalne, torej estetske organizacije in strukturiranja ne bi zvoki nikdar presegli svoje "naravne estetskosti«, ne bi prodrli do oblikovanja glasbeno lepega in gotovo ne do kvalitete označevanja. Navedeno dobiva še večji pomen $\mathrm{v}$ perspektivi druge od dveh omenjenih realnosti, in ta je izražanje. Ko ekspresivna glasba uporablja zvoke, se jih ne poslužuje le kot navadnih fizikalnih in akustičnih objektov, ampak kot simbolov: njena lepota in tako tudi izraz izhajata iz globine umetnikovega doživljanja in ustvarjalne intuicije. Ekspresivna glasba pokaže nesporno poslušalcu več kakor predstavlja samo kot zvočni ali akustični fenomen. ${ }^{12}$ Pri glasbenem izrazu ne gre le za označujoče sposobnosti in sile zvoka, ampak tudi za možnost, da jim ustvarjalec, človek, vtisne določen pečat lastnega doživljanja.

Pri tezi, da imajo nekatera glasbena dela lahko glasbeni in izvenglasbeni smisel, je važno, da v problematiki pomena glasbe in glasbenega izraza ta in oni smisel jasno razlikujemo. Čeprav ima, kot poudarja Fubini, vsako glasbeno delo neskončno ravni ali stopenj pomenov, se nam - enako kot njemu - ne zdi problem, ali glasba črpa svoje pomene iz sveta emocij in občutij ali pa odkriva misel, globino bitja ali nekaj drugega, bolj ali manj nepomemben. ${ }^{13}$ Nasprotno, vprašanje izvenmuzikalnega smisla, ki je tesno povezano $\mathrm{z}$ vprašanjem njegova pomena, je zelo važno. Vendar, ko govorimo o izvenglasbenem smislu glasbenega dela, tu ne mislimo na izvenglasbene vrednosti, kot so ali morejo biti njegova kulturna, zgodovinska ali etična vrednost ( $\mathrm{ki}$ jih lahko ugotovimo $\mathrm{z}$ znanstveno analizo), niti ne razumljivost in smisel, ki bi bila lastna specifično glasbeni misli, torej na razumljivost in spoznavnost specifično glasbene narave, ki sta nerazdružljivo povezani z glasbeno percepcijo: kot izvenglasbeni smisel pojmujemo stalno spoznavnost neke izvenglasbene vsebine $\mathrm{v}$ glasbi in skozi glasbo, in to takšne vsebine, ki jo je lahko ne samo $\mathrm{z}$ glasbenimi sredstvi izraziti, ampak tudi $\mathrm{s}$ samim poslušanjem glasbenega dela doživeti. Če pa tako pojmovano spoznavnost, ki je

${ }^{11}$ Ko smo navedli izhodišče Hegla o osnovni istovetnosti glasbe in zvoka, je torej bilo treba to dopolniti in razširiti. Isto je treba storiti tudi $\mathrm{z}$ omenjenim stališčem Gisèle Breletove, za katero je glasba čistemu občutku dosti bližja kot druge umetnosti. Čeprav se to zdi nesporno, je treba poudariti, da se glasbe nikakor ne da reducirati na občutek. To tudi Breletova v skrajnem smislu ne misli.

12 Prim. Muzikološki zbornik, III, 1967, 95-104.

${ }_{13}$ Fubini E., Struktura i vremenitost muzike, Zvuk 1969, št. 91, 1-6. 
vsebovana $\mathrm{v}$ nekaterih glasbenih delih, imenujemo smisel, ki ga delo vsebuje, je to zato, da poudarimo, da bi odsotnost vsake izvenglasbene spoznavnosti $\mathrm{v}$ takšnih ekspresivnih glasbenih delih pomenila nesmisel in notranje protislovje tako po sebi kot glede na poslušalca. Tako bi se o ekspresivni glasbi $\mathrm{v}$ pravem in popolnem smislu niti ne smelo razpravljati. Ferguson je med mnogimi drugimi upravičeno opozoril na dejstvo, da je $\mathrm{v}$ nasprotju $\mathrm{s}$ sentimentalističnimi koncepcijami »izraz v pravem smislu besede več kot vzbujanje občutij. Izraz je spoznavno izražanje ne samo golih občutij, ampak tudi misli; da glasba ustvari izraz, mora spodbuditi misel in občutje ... ${ }^{14}$ Izvenglasbeni smisel, ki je vsebovan v ekspresivnem glasbenem delu, predstavlja torej spoznavno izraženo realnost, ki je opazna s samim poslušanjem glasbenega dela. Vendar pa ni izrazni smisel ali izvenglasbeni smisel bistvena notranja zahteva glasbe $\mathrm{v}$ celoti, niti ne obstaja $\mathrm{v}$ glasbenem delu neodvisno od glasbenega smisla ali pa samo zaradi sebe. Reprezentativna funkcija glasbe ni njen glavni poklic. ${ }^{15}$ Glasba ne označuje in ne izraža »esencialno«, po nujnosti svoje univerzalne biti, temveč »akcidentalno«, to je, če hoče. ${ }^{16}$ $\mathrm{Ni}$ nujno, da je izvenglasbeni smisel prisoten $\mathrm{v}$ glasbenem delu in pri tem tudi ni nujno, da je to zmanjšano $v$ svoji čisto umetniški in estetski vrednosti. Izvenglasbeni smisel je odsoten iz čiste glasbe, to dejstvo pa te niti najmanj ne naredi estetsko manj vredne. Vendar izvenglasbeni smisel ne more biti niti $\mathrm{v}$ enem primeru odsoten iz ekspresivne glasbe, ne da bi ta glasba prenehala biti ekspresivna.

Čeprav ni izvenglasbeni smisel v glasbenem delu samemu sebi namen in ga nekateri celo imajo za »zunanji« element glasbe, za smet, ki kali njeno čistost, pa ta smisel ni ekspresivnemu delu primešan ali dodan na nek umeten način, temveč nasprotno izhaja spontano iz glasbenega tkiva ekspresivnega glasbenega dela prav $\mathrm{v}$ tisti meri kot je to delo glede na svojo izvenglasbeno spoznavnost označujoče in izrazno. Izražanje izvenglasbenih vsebin skozi glasbo je torej nosilec izvenglasbenega smisla ekspresivnega glasbenega dela. Ta smisel je toliko bolj realen, kolikor bolj je realen izraz izvenglasbene vsebine $v$ glasbenem delu. Čimbolj adekvatno je izvenglasbena vsebina izražena, toliko več izraznega oziroma izvenmuzikalnega ima delo. To izražanje izvenglasbenih vsebin z glasbo pa je lahko toliko bolj dovršeno, kolikor bolj je vsebina, ki jo mora izraziti, glasbeno izrazna. Glede na to, da pomeni izražati izpovedovati in sporočati, napraviti prisotno, eksteriorizirati, je očitno to, da se ne izraža zato, da ostane izraženo nerazumljivo, ampak zato, da bodo drugi to doživljali in razumeli. Izražanje ni samo dajanje iz sebe in skozi sebe, ampak je tudi prikazovanje in predstavljanje drugemu ali za druge ter je potemtakem tudi pot za komunikacijo. Ekspresivnosti brez komunikacije si ne moremo misliti. Odtod tudi sicer

${ }^{14}$ Ferguson N., Music as Metaphor. The Elements of Expression, Minneapolis 1960, 14-15.

15 Souriau E., Odnos među umjetnostima, Sarajevo 1958, 146.

16 Roland-Manuel, Sonate que me veux-tu?, Lausanne 1957. 
izhaja človeški in družbeni značaj glasbe kot izražanje, a to nazadnje pomeni ekspresivne glasbe. Izražati in ne vedeti, kaj se izraža, ali poslušati ekspresivno glasbeno delo in nikakor ne moči doumeti njegov izrazni smisel ali izvenglasbeni pomen (kar ne vključuje tudi estetsko vrednost), bi bilo notranje protislovje, če že ne absurd ekspresivne glasbe in izražanja izvenglasbenih vsebin $\mathbf{z}$ glasbo nasploh. Osebni izraz dobiva smisel samo glede na doživljanje in spoznavno moč avtorja in poslušalca.

Vendar glasbeni izraz kakor tudi vsako umetniško izražanje ne izhaja nujno iz zavestne potrebe ustvarjalca po komunikaciji z drugimi. Znano je, da so bili in so še ustvarjalci, ki ustvarjajo, kot da govore le samemu sebi, samo iz notranjega impulza in iz same potrebe po izpovedovanju kot takšnem, po ustvarjanju iz sebe, neodvisno od drugih in od njihovih možnosti ali sposobnosti razumevanja, doživljanja in uživanja. Dejansko se skladatelj najpogosteje, pa naj se tega zaveda ali ne, to hoče ali noče, izraža zato, da ga nekdo sliši, doživi in razume tisto, kar s svojim delom izraža. Če vzamemo vpoštev ne le umetnika $\mathrm{v}$ času njegovega ustvarjanja, ampak tudi dovršeno delo, je to nedvomno ustvarjanje zato, da ga nekdo drug doživi in spozna. Po naziranju nekaterih je v skrajnem smislu že tako vsaka glasba pisana za občinstvo in glede nanj, in če njen ustvarjalec to hoče ali noče, mu to ostane na vsak način zavestno ali nezavedno prisotno. ${ }^{17}$

Poleg izvenglasbenega smisla, ki ga glasbeno delo lahko ima, ima in mora imeti vsako glasbeno delo v tisti meri kot je umetniška tvorba, tudi svoj čisto specifičen glasbeni smisel, ki je neločljiv od njegove oblikovne strukture. Glasbeni smisel je torej prvotna realnost vsakega glasbenega dela, ki ima estetsko vrednost. Ta glasbeni smisel potemtakem obstaja $\mathrm{v}$ tisti meri, $\mathrm{v}$ kateri poseduje glasbeno delo, v katerem je realiziran, muzikalno umetniško vrednost, neodvisno od vsakega izvenglasbenega smisla, vsebine ali izražanja. Čeprav je glasbeni smisel tesno povezan $\mathrm{z}$ glasbeno vsebino in je tej imanenten, izhaja $\mathrm{v}$ ekspresivnem glasbenem delu izrazni smisel prav iz njega. če ima čista glasba estetsko vrednost prav toliko, kolikor je vsebina v glasbenem delu čiste glasbe imanentna njegovi figuri, je estetska vrednost ekspresivnega glasbenega dela $\mathrm{v}$ imanentnosti izraznega oziroma izvenglasbenega smisla $\mathrm{v}$ glasbenem smislu, medtem ko njegova izrazna vrednost ni nujno vedno $\mathrm{v}$ tem.

Ker sta izvenglasbeni in glasbeni smisel tako tesno povezana in ker je izražanje izvenglasbenih vsebin z glasbo glasbeni izraz (dasiravno ni izključno izraz glasbenega), je izvenglasbeni smisel v ekspresivni glasbi $v$ njej prisoten in spoznaven samo skozi zvočno tkivo, po zvočni materiji dela, skozi njo (kljub temu, da je lahko v večji ali manjši napetosti s samim glasbenim smislom dela kot takšnim ter $\mathrm{z}$ njegovimi formalnimi zahtevami in tendencami). Izvenglasbeni in glasbeni smisel se torej pokrivata samo toliko, kolikor je estet-

${ }_{17}$ Machabey A., Traité de la critique musicale, Paris 1947, 37. 
ska vrednost ekspresivnega glasbenega dela realizirana. Izvenglasbeni smisel ekspresivnega glasbenega dela izhaja vedno iz zvočnega tkiva in iz njegovih lastnosti, ki jih karakterizira nek izvenglasbeni spoznavni pomen. Te lastnosti pripadajo kajpak bolj ali manj glasbenemu smislu dela. Seveda ima smisel estetsko vrednost, še več, on je estetska vrednost, ta pa je njegov kriterij in bistveni pogoj eksistence. Nasprotno pa ima zvočno "tkivo" glasbenega dela predvsem fizikalno in akustično vrednost, ki jo je treba šele vzdigniti na stopnjo estetske vrednosti in postaviti $\mathrm{v}$ njeno službo. V skrajnem smislu zvok ni cilj glasbe, ampak njeno sredstvo. Zvok je potemtakem tudi sredstvo njene estetske vrednosti, material ali gradivo, s katerim se ta vrednost, ki je cilj, gradi in izgradi.

Glasbeni smisel je lahko realiziran v ekspresivnem glasbenem delu kakor tudi v delu čiste glasbe $\mathrm{v}$ različnih stopnjah. Vendar je vsaj pri velikih skladateljih izredno redko, da je glasbeni smisel v ekspresivnem glasbenem delu odsoten $\mathrm{v}$ tolikšni meri, da ga privede do glasbenega nesmisla. Tedaj bi tudi sama ekspresivna vrednost prenehala obstajati glede na to, da se $\mathrm{v}$ glasbenem delu realizira skozi estetski element in da je po naravi glasbena. Pri Wagnerju je npr. estetska smiselnost dela včasih znatno podvržena izvenglasbeni smiselnosti, vendar sta glasbeni smisel in estetska vrednost $\mathrm{v}$ takšnih primerih daleč od tega, da bi bila reducirana na svoje nasprotje. Vsekakor ekspresivna vrednost dela lahko obstaja do določene meje neodvisno od estetske vrednosti dela. Z umetniškega stališča pa je nesporno, da ima estetska vrednost vselej primat nad izrazno vrednostjo glasbenega dela, tako kot ga ima glasbeni smisel pred izvenglasbenim.

\section{SUMMARY}

According to Hegel, sound and music are essentially identical. However, the effect of music does not only depend on sound as an element to be used by music, but also on its concrete contents. The nature of sound as an object does not come into question in music, but sound has pre-eminence in music as subject or material. This ontological priority does not exclude the quality of sound as a symbol, although its characterisation is strictly limited to the field of its inherent possibilities for characterisation. Musical utterance is not only specified by its use of special material, sound, but also by the fact that, in distinction to nonartistic means of expression, it finds its justification and sense only as an aesthetic manifestation. A musical work, neither expressive nor programmatic, does not have only sound or sonority as its subject matter, nor their exclusively physical production, their characterisation or expression as such for its highest aim, but its own aesthetic structure. However, this must not exclude, but can include, specific musical characterisation and expression. Although we must differentiate clearly between the musical and the extra-musical sense of a work, these two concepts cannot be separated. The aesthetic value of music is paramount to its value in characterisation and expression. Only a sythesis of these two values can give a perfect artistic sense to expressive music. 